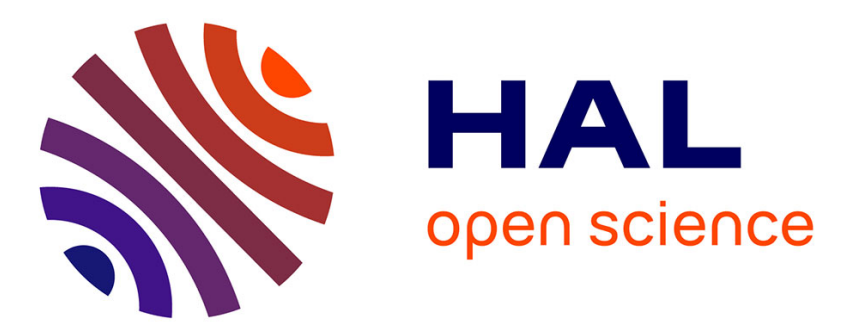

\title{
Active spectral phase control by use of an acousto-optic programmable filter in high-repetition-rate sub-80 fs nonlinear fiber amplifiers
}

Dimitris N. Papadopoulos, Igor Martial, Marc Hanna, Frédéric Druon, Patrick Georges

\section{To cite this version:}

Dimitris N. Papadopoulos, Igor Martial, Marc Hanna, Frédéric Druon, Patrick Georges. Active spectral phase control by use of an acousto-optic programmable filter in high-repetition-rate sub- 80 fs nonlinear fiber amplifiers. Optics Letters, 2008, 33 (13), pp 1431-1433. hal-00533393

\section{HAL Id: hal-00533393 https://hal.science/hal-00533393}

Submitted on 30 Mar 2012

HAL is a multi-disciplinary open access archive for the deposit and dissemination of scientific research documents, whether they are published or not. The documents may come from teaching and research institutions in France or abroad, or from public or private research centers.
L'archive ouverte pluridisciplinaire $\mathbf{H A L}$, est destinée au dépôt et à la diffusion de documents scientifiques de niveau recherche, publiés ou non, émanant des établissements d'enseignement et de recherche français ou étrangers, des laboratoires publics ou privés. 


\title{
Active spectral phase control by use of an acousto- optic programmable filter in high-repetition-rate sub-80 fs nonlinear fiber amplifiers
}

\author{
D. N. Papadopoulos, ${ }^{*}$ I. Martial, M. Hanna, F. Druon, and P. Georges \\ Laboratoire Charles Fabry de l'Institut d'Optique, CNRS, Université Paris Sud, 91127 Palaiseau, France \\ *Corresponding author: dimitris.papadopoulos@institutoptique.fr
}

Received February 20, 2008; revised May 26, 2008; accepted May 26, 2008;

posted May 29, 2008 (Doc. ID 92966); published June 23, 2008

\begin{abstract}
We report the generation of sub- $80 \mathrm{fs}$ pulses with energy in the $100 \mathrm{~nJ}$ range at $1050 \mathrm{~nm}$ and a repetition rate up to $164 \mathrm{kHz}$ based on a nonlinear fiber amplification system combined with an active control of the spectral phase. This control is performed by an acousto-optic programmable dispersive filter operated at a multiple of its acoustic repetition rate. This result opens up its possible use in highly nonlinear fiber chirpedpulse amplification setups. (C) 2008 Optical Society of America

OCIS codes: $060.2320,320.5540,140.3510$.
\end{abstract}

Thanks to their geometry and design, Yb-doped fibers feature outstanding thermo-optical properties, high saturation fluence, and high optical pumping efficiency $(\sim 80 \%)$. However, the major drawback of ultrashort pulse amplification in doped fibers is the long confined propagation length in the material, which limits energy scaling because of harmful nonlinear pulse distortions. Another limitation of femtosecond fiber amplifiers is the achievable pulse duration: The $\mathrm{Yb}$ ion in glass exhibits a gain bandwidth of approximately $40 \mathrm{~nm}$, well below the value of $\mathrm{Ti}: \mathrm{Sa}$.

To increase the bandwidth and energy of amplified pulses in fiber systems, the most investigated solution consists in controlling nonlinear effects. For example, specific fiber chirped-pulse amplifiers have been designed to generate high-energy pulses in the presence of large amounts of accumulated nonlinear phase [1-3]. Nonlinear effects can also be exploited rather than avoided to take advantage of the spectral generation imparted by self-phase modulation (SPM). This is the basis of the parabolic regime [4,5], which has attracted a lot of attention and has led to the generation of very short amplified pulses. Recent experiments have demonstrated increasing sub-100 fs pulse energies by operating in even more nonlinear regimes while controlling the spectral phase via a mechanism compensating between SPM and third-order dispersion [6,7].

These methods to reach higher energies and shorter pulse widths are increasingly complex in terms of the propagation regime and may require a high accumulated nonlinear phase, which calls for active control of the spectral phase to guarantee good compressed pulse quality. Furthermore, the large bandwidth obtained through nonlinear effects implies that higher-order dispersion terms need to be compensated, requiring a compression system more sophisticated than the typical grating pair. As shown previously, both theoretically [8] and experimentally [9], spectral preshaping can be used for the compensation of nonlinear pulse distortions in fiber amplification systems, even in the presence of high SPM. Such active spectral phase control is routine in highenergy Ti:Sa systems.
In this Letter, we investigate, for the first time to our knowledge, the potentiality of the combined operation of a large-mode-area (LMA) double-clad Ybdoped fiber amplifier with an acousto-optic programmable filter (Dazzler, Fastlite) for active spectral phase and amplitude control [10] for femtosecond pulse amplification. Since the main advantage of fibers consists in the potentially high repetition rate with average power, we have operated the Dazzler in a novel configuration at a harmonic of its acoustic repetition rate. In contrast to pure parabolic amplification, the pulses are amplified and both temporally and spectrally broadened in an unconventional nonlinear regime dominated by SPM in the presence of gain and positive group-velocity dispersion (GVD, nonlinear length $L_{\mathrm{NL}} \asymp 2.6 \mathrm{~cm}$ and dispersion length $L_{\mathrm{D}} \asymp 1.2 \mathrm{~m}$ ) [11]. Our purpose is to investigate the ability of the Dazzler, in this demanding case, to compensate for the complicated spectral phase components of the amplified pulses at a high repetition rate and therefore its potentiality as an intermediate active element of a future more complex chirped-pulse amplification system. The output pulses are fully characterized by means of a frequency-resolved optical gating (FROG) setup and are independently cross checked by intensity autocorrelation ( $50 \mathrm{ps}$ delay range) and spectrometer measurements. The genera-

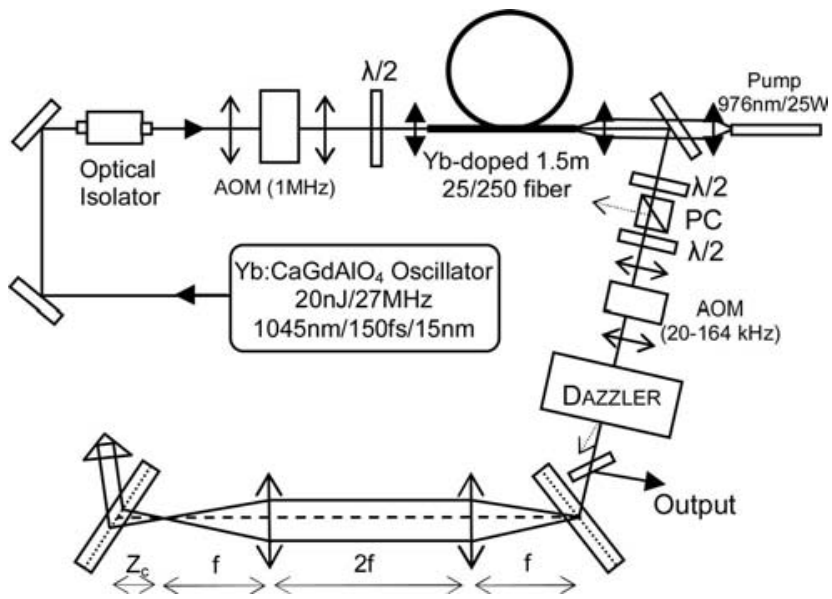

Fig. 1. Experimental setup. 
tion of high-quality $56 \mathrm{fs}, 230 \mathrm{~nJ}$ pulses at $20 \mathrm{kHz}$ is demonstrated, while high-quality sub- $80 \mathrm{fs}$ pulses are obtained as a result of the sufficient active spectral phase control by the Dazzler at repetition rates as high as $164 \mathrm{kHz}$.

Our system consists of a diode-pumped passively mode-locked bulk $\mathrm{Yb}: \mathrm{CaGdAlO}_{4}$ laser oscillator, followed by the diode-pumped polarization-maintaining (PM) LMA Yb-doped fiber amplifier (YDFA), and a compression stage based on either a conventional grating pair or a Dazzler or a combination of both (Fig. 1). The oscillator delivers $20 \mathrm{~nJ}$ in $150 \mathrm{fs}$ pulses at $27 \mathrm{MHz}$. The repetition rate is reduced to $950 \mathrm{kHz}$, and about $10 \mathrm{~nJ}$ pulses are seeded into the amplifier. The YDFA consists of a $1.5 \mathrm{~m}$ long double-clad $\mathrm{Yb}$ doped PM-LMA fiber $(25 / 250 \mu \mathrm{m}, \mathrm{NA}=0.06$, Liekki), pumped at $976 \mathrm{~nm}$, and exhibits absorption of $11.2 \mathrm{~dB} / \mathrm{m}$. Both fiber ends are angle cleaved at $8^{\circ}$ to suppress parasitic lasing effects. The pump power is increased to $6 \mathrm{~W}$, yielding an output of $1.2 \mathrm{~W}$. At this level, the amplifier delivers about $80 \%$ linearly polarized $3.2 \mathrm{ps}$ pulses of $41.5 \mathrm{~nm}$ bandwidth. About $500 \mathrm{~nJ}$ of maximum pulse energy reaches the compression stage after further reduction of the repetition rate between 20 and $164 \mathrm{kHz}$.

Initially, compression is performed either by a high-efficiency 1250 line/mm transmission-grating pair compressor (GC) or a Dazzler operating at a $20 \mathrm{kHz}$ repetition rate. Next, compression is performed by combination of a Dazzler with the GC at repetition rate up to $164 \mathrm{kHz}$. Two different Dazzler modules are used. The first one, used in the direct compression of the YDFA pulses, employs a $45 \mathrm{~mm}$ long $\mathrm{TeO}_{2}$ crystal providing a spectral resolution of $1 \mathrm{~nm}$ and a maximum achievable group delay of about $5 \mathrm{ps}$, large enough to compress the pulses without a GC, but restricting the repetition rate to about $20 \mathrm{kHz}$. To increase the repetition rate, a smaller crystal is used operating in a different configuration: Optical pulses emitted at a multiple of the Dazzler acoustic repetition rate interact with the same acoustic wave at different positions in the crystal. However, this results in the decrease of the Dazzler shaping capacity, because of the reduction of the opticalacoustic interaction time, necessitating the use of a GC for sufficient GVD compensation.

Thus, the second Dazzler employs a $25 \mathrm{~mm}$ long $\mathrm{TeO}_{2}$ crystal $(0.6 \mathrm{~nm}$ spectral resolution and $3 \mathrm{ps}$ maximum group delay) and is combined with the 1250 line/mm GC. The acoustic repetition rate of the Dazzler is then $41 \mathrm{kHz}$, while operation at 82,123 , and $164 \mathrm{kHz}$ is also performed by interaction with the same acoustic wave of one up to four optical pulses. The interaction time is maximized, to achieve both high diffraction efficiency and sufficient spectral phase control, by progressive decrease of the negative GVD applied by the Dazzler from -15000 to $-4000 \mathrm{fs}^{2}$ at 41 and $164 \mathrm{kHz}$, respectively.

In Fig. 2 the output pulses, retrieved from a second-harmonic generation FROG measurement, are presented in the case of pulse compression by either the GC or the long crystal Dazzler. As expected,
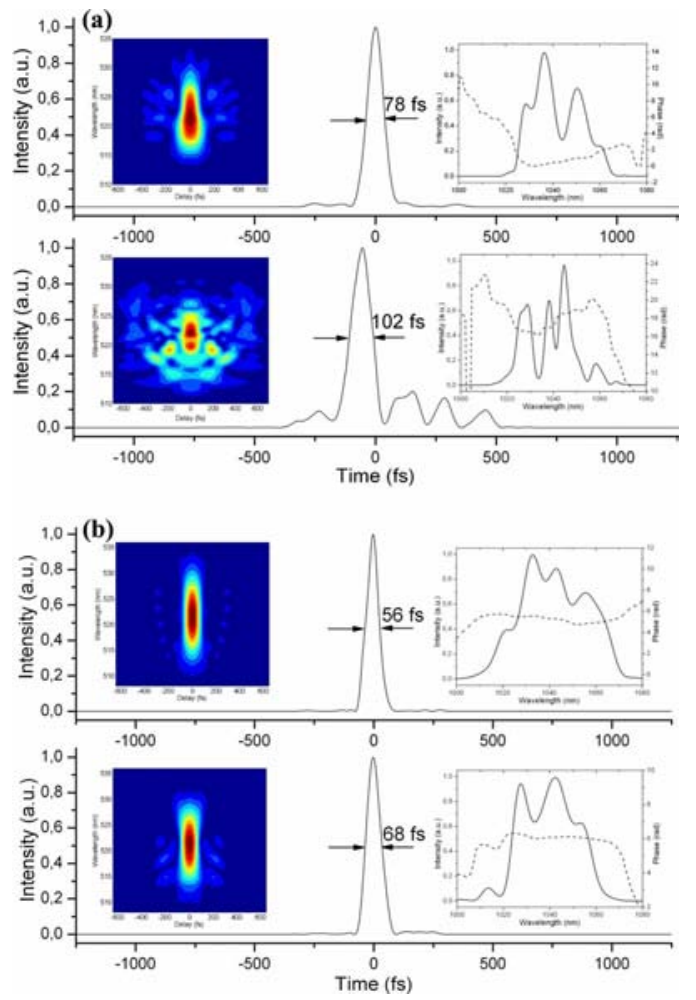

Fig. 2. (Color online) Retrieved temporal intensity profile of the compressed pulses (a) with a grating pair and (b) a Dazzler at $6 \mathrm{~W}$ (upper part) and $5 \mathrm{~W}$ (lower part) of pump power (FROG traces and retrieved spectra are shown as insets).

the grating-based compression quality features a strong power level dependence as a result of the induced spectral shaping and the consequent complex accumulated nonlinear phase [7]. Efficient compression was possible only at the highest pump level of $6 \mathrm{~W}$ [190 nJ after compression and estimated nonlinear phase $\Phi_{\mathrm{NL}} \asymp 23.5 \pi$, upper part of Fig. 2(a)], while for lower power uncompensated spectral phase resulted in poor compression quality. In Fig. 2(a) (lower part) this is demonstrated for $5 \mathrm{~W}$ of pump power (155 nJ after compression, $\Phi_{\mathrm{NL}} \asymp 17.4 \pi$ ). Furthermore, bandwidth limitations of the gratings resulted in decreased efficiency $(<36 \%$ at highest power $)$ and spectral filtering, seriously limiting the achievable pulse duration.

On the other hand, when for the exact same conditions the GC was replaced by the Dazzler, both compression efficiency (constantly $\sim 50 \%$ ) and pulse quality were maintained almost unaffected by the power level, i.e., the extensively varying spectral phase content of the pulses. In Fig. 2(b) the resulting output pulses are presented for 6 and $5 \mathrm{~W}$ pump power (upper and lower part, respectively). In both cases an almost flat spectral phase is obtained (corresponding Strehl ratios of 0.89 and 0.82 at 6 and $5 \mathrm{~W}$ ), resulting in pulse durations of $68 \mathrm{fs}$ ( $5 \mathrm{~W}$ pump power) and $56 \mathrm{fs}$ at the highest pump power (230 nJ output energy, i.e., 4.1 MW peak power).

To reach a higher repetition rate while maintaining sufficient spectral phase control, we performed pulse compression with a combination of the $25 \mathrm{~mm}$ crystal 

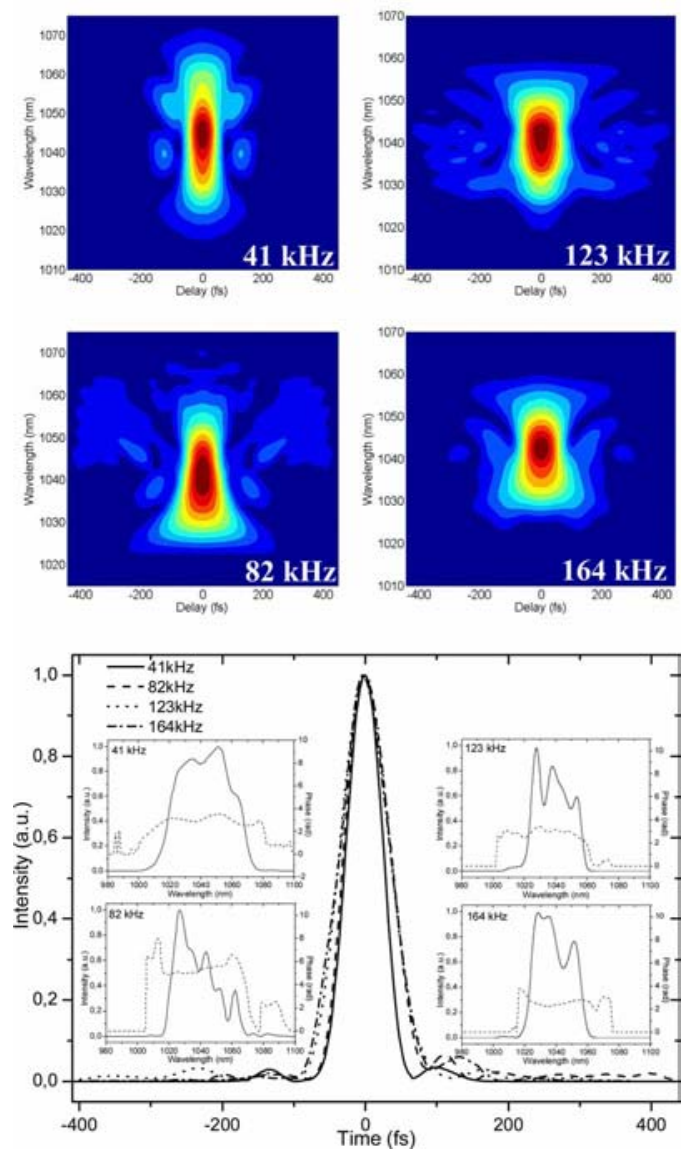

Fig. 3. (Color online) FROG traces of the Dazzler+grating compressed pulse at $41-164 \mathrm{kHz}$ (upper part) and corresponding retrieved temporal intensity profiles (retrieved spectra are shown as insets).

Dazzler and the GC previously used. Careful synchronization along with optimized distribution of the GVD compensation between the Dazzler and the grating compressor permitted power-independent overall spectral phase compensation and optimized pulse compression for repetition rates of $41,82,123$, and $164 \mathrm{kHz}$. In Fig. 3 are presented the corresponding FROG traces (upper part) and the retrieved output pulses (lower part) as well as the retrieved spectral intensity and phase (insets) in the case of maximum pump power $(6 \mathrm{~W})$ at each repetition rate.

The pulse durations are 58, 72, 76, and 78 fs at 41 , 82,123 , and $164 \mathrm{kHz}$ respectively, with temporal Strehl ratios of $0.84,0.83,0.87$, and 0.86 , corresponding to sufficiently flattened spectral phase. The increased pulse duration at repetition rates higher than $41 \mathrm{kHz}$ is expected: Multiple optical pulse interaction with the same acoustic wave at different positions in the Dazzler crystal results in a small amount of uncompensated material dispersion. Because the acousto-optic interaction time decreases with increasing repetition rate from 41 to $164 \mathrm{kHz}$, Dazzler diffraction efficiency decreased from $60 \%$ to $32 \%$, resulting in an overall compression efficiency of $38 \%$ to $18 \%$ and pulse energies of $185,180,105$, and $90 \mathrm{~nJ}$, respectively.

In conclusion, we have demonstrated the use of a Dazzler for active spectral phase control of a nonlinear LMA YDFA system providing complex spectral phase pulses. Operation at repetition rates up to $164 \mathrm{kHz}$ is reported. To our knowledge this work constitutes the first experimental proof of the potentiality of a combined operation of the Dazzler with YDFA systems. We believe that the presented system, providing independent active spectral intensity and phase control of arbitrarily high order, could be successfully implemented in a future chirped-pulse amplification setup for the production of sub- $100 \mathrm{fs}$ pulses in the $100 \mu \mathrm{J}$ energy range at repetition rates greater than $100 \mathrm{kHz}$.

The authors acknowledge the financial support of L'Agence Nationale de la Recherche (ANR) under the HIPOLYFF program. D. N. Papadopoulos acknowledges the financial support of the Région Ile de France for his postdoctoral position. We thank Catherine Leblanc (Laboratoire pour l'Utilisation des Lasers Intenses, France) for the loan of the long crystal Dazzler and Liekki for the loan of the fiber.

\section{References}

1. L. Shah, Z. Liu, I. Hartl, G. Imeshev, G. Cho, and M. Fermann, Opt. Express 13, 4717 (2005).

2. L. Kuznetsova and F. W. Wise, Opt. Lett. 32, 2671 (2007).

3. A. Chong, L. Kuznetsova, and F. W. Wise, J. Opt. Soc. Am. B 24, 1815 (2007).

4. M. E. Fermann, V. I. Kruglov, B. C. Thomsen, J. M. Dudley, and J. D. Harvey, Phys. Rev. Lett. 84, 6010 (2000).

5. J. Limpert, T. Schreiber, T. Clausnitzer, K. Zöllner, H.-J. Fuchs, E.-B. Kley, H. Zellner, and A. Tünnermann, Opt. Express 10, 628 (2002).

6. D. N. Papadopoulos, Y. Zaouter, M. Hanna, F. Druon, E. Mottay, E. Cormier, and P. Georges, Opt. Lett. 32, 2520 (2007).

7. Y. Zaouter, D. N. Papadopoulos, M. Hanna, J. Boullet, L. Huang, C. Aguergaray, F. Druon, E. Mottay, P. Georges, and E. Cormier, Opt. Lett. 33, 107 (2008).

8. T. Schreiber, D. Schimpf, D. Müller, F. Röser, J. Limpert, and A. Tünnermann, J. Opt. Soc. Am. B 24, 1809 (2007).

9. J. van Howe, G. Zhu, and C. Xu, Opt. Lett. 31, 1756 (2006).

10. F. Verluise, V. Laude, Z. Cheng, C. Spielmann, and P. Tournois, Opt. Lett. 25, 575 (2000).

11. C. Finot, F. Parmigiani, P. Petropoulos, and D. Richardson, Opt. Express 14, 3161 (2006). 